Book Review

(C) Journal of International Students

Doi: $10.32674 /$ jis.v10i4.2729

ojed.org/jis

\title{
Manual for Developing Intercultural Competencies: Story Circles
}

\author{
Darla K. Deardorff, 2020. UNESCO: ISBN-13 978-92-3-100331-8
}

Reviewed by Jean Baptiste Diatta, Boston College Center for International Higher Education, Massachusetts, USA.

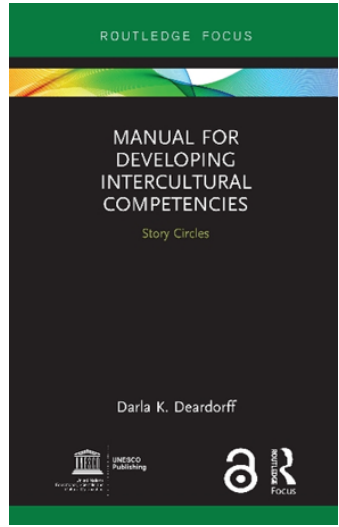

The Manual for Developing Intercultural Competencies: Story Circles, written by Darla K. Deardorff, offers a brief overview of approaches and tools for fostering intercultural competencies. Perhaps most importantly, she provides a detailed presentation of a tool called Story Circles, which can be used in different contexts and situations around the world for the development of intercultural competencies. The Story Circle methodology was adapted for the purpose of developing a human right-centered approach to intercultural competencies. Story Circles put the emphasis on "fundamental elements of intercultural competencies development, including respect, listening, curiosity, selfand other awareness, reflection, sharing, empathy, and relationship building" (p. 13).

The manual is divided into three main parts. The first part, entitled "Background," provides the context from which this manual emerges: the quest for peace in general, more specifically, UNESCO's work to empower learners of all ages by helping them to develop a sense of empathy and solidarity, and to act as global citizens "in line with the 2030 Agenda for Sustainable Development, in particular the Sustainable Development Goals 4 (on education) and 16 (to promote just, peaceful, and inclusive societies)" (p. 2). This section also describes the publication as putting into effect the UNESCO 2013 publication, Intercultural Competencies: Conceptual and Operational Framework, which addressed the importance of developing capacity to manage cultural diversity and clarifies related concepts. Additionally, the first part offers a rich survey of different conceptions of intercultural competences, as well as 
tools and approaches aimed at fostering them. This culminates with an attempt at summarizing different conceptions of intercultural competences as follows: intercultural competences are "about improving human interactions across difference, whether within a society (differences due to age, gender, religion, socio-economic status, political affiliation, ethnicity, and so on) or across borders" (p. 5).

The second section, "Story Circles," presents the intercultural tool designed for the development of relevant competencies. It is meant to be used in different contexts, for different groups of people, and in formal or informal instructional settings. Moreover, this tool is designed to function even in situations that have limited resources. The tool can be efficiently managed by "those who may not have a strong background in intercultural knowledge and theory" (p. 13).

Part II also specifies the different contexts in which Story Circles can be useful for the development of intercultural competencies. These include teacher education, international projects, community development, intercultural dialogue, healthcare training, and police training. Further, the key assumptions that undergird Story Circles are presented, concluding with the assertion that Story Circles rest on two values: respect and openness. Two related assumptions underlay Story Circles practices: first, that human persons are all interconnected through human rights, and second, each person has an inherent dignity and worth.

After presenting the philosophical-moral foundation of the Story Circles, Part II addresses practicalities related to their implementation. These include the determination of guidelines for the use of Story Circles, the role and training of the facilitator, and the content and organization of the Story Circles. An extensive list of material related to the facilitation of Story Circles, as well as the development of intercultural competences, is also offered. A number of intercultural communication issues that might arise in Story Circle practices are discussed, as well as mitigation techniques.

Part III, "Supporting Material," can be regarded as an addendum. It presents the different materials alluded to in Part II needed for the facilitation of Story Circles. Among them are the UNESCO Story Circles Information Sheet, a general handout (for small groups), Story Circles prompts (along with criteria for developing/adapting intercultural prompts), and finally guidelines for facilitators. These guidelines include, among other things, suggestions on debriefing and concluding Story Circles, some guidelines on how to use Story Circles with children and youth, and how to create a safe space. Additionally, Part III offers a general train-the-trainers outline, a list of frequently asked questions, and the UNESCO evaluation form.

Three key features constitute the strength of the manual: a solid philosophical and moral foundation, accessibility, and practicability. In fact, the philosophical foundation of the Story Circles practice is the interconnectedness of human persons (through human rights) and the inherent dignity and worth that any person has by the simple fact of being a human person. Thus two moral imperatives follow, respect and openness to others (e.g., to learn from them). Intercultural competences are intrinsically bound to those two values. Moreover, the interrelatedness of the two philosophical assumptions, the two moral imperatives, and the concept of intercultural competences must be emphasized. 
The manual's simplicity makes it readily accessible. In fact, it does not require a background in or extensive knowledge of intercultural competence or communication in order to be able to understand the concepts and experience it proposes. Moreover, the language, as well as the detailed guidance offered throughout the manual, make it accessible to everyone.

The practicability of the manual stems mainly from the fact that it sets realistic goals. It does not require many resources; it is not lengthy; and the methodology it proposes can be adapted in different settings. Anticipating the intercultural communication challenges that might arise in a context of intercultural interaction, and tips on how to prevent them or mitigate them if they arise, add to the manual's usefulness - which should characterize any manual worth of its name.

Despite the author's laudable intent to make the manual universally useful, the methodology/tool suggested might not work for all contexts, given its emphasis on the constitution of diverse groups (gender, experience, social status). In fact, in cultural contexts with rigid castes, class structures, or pronounced gender divides, conversation could be easily blocked, which would compromise the experience.

Another issue is the affirmation that "we are all interconnected through human rights" (p. 17). The interconnectedness of human beings is an ontological fact that precedes any articulation of human rights. Of course, I understand the intent of tying Story Circles to human rights, but the way it is done, and the place given to human rights in this context is, at least philosophically, problematic. Simply said, our connectedness owes nothing to human rights. It suffices to underscore that there is no agreement on what human rights are and what they should entail. Thus, there is little to gain, but much to lose in erecting human rights as the locus of our connectedness.

The Manual for Developing Intercultural Competencies: Story Circles is a book worth reading for people working to promote intercultural dialogue or competences in the context of youth and professional development. Of course, the manual could also be useful to academics (students, faculty, and administrators) interested in study abroad experiences or international students. It is a valuable contribution to the effort of helping people acquire intercultural competences, which are needed for meaningful and effective navigation in today's globalized world.

JEAN BAPTISTE DIATTA, PhD candidate, is a Research Assistant in the Center for International Higher Education at Boston College. His major research interests lie in the area of quality assurance in higher education, learning outcomes design and assessment, internationalization of higher education, and intercultural competences. Email: jeanbaptiste.diatta@bc.edu 